\title{
Место и роль аристократии в традиционных обществах Дальнего Востока
}

\begin{abstract}
Аннотачия: статья посвящена сравнительному изучению положения сочиальной группы наследственной аристократии в традииионных обществах Дальнего Востока. Анализируются состав и роль аристократии в китайских империях разных периодов и в соседних с Китаем странах, входивших в то или иное время в ареал распространения китайской политической культуры. Делается попытка оченить уровень монополизачии аристократией высших государственных должностей в азиатских обществах различного типа.
\end{abstract}

Ключевые слова: история, Дальний Восток, сочиальная группа, аристократия, бюрократия, чиновничество, император, государственный аппарат, клан, род.

$\Pi$ онятие «аристократия» не имеет в научной практике строгого определения (в большинстве случаев оно употребляется достаточно абстрактно: как обозначение высшего слоя общества), поэтому следует пояснить, о чем пойдет речь в данном случае. В абсолютном большинстве традиционных обществ наличествует высшая социальная группа, состоящая в зависимости от размеров страны из нескольких десятков или сотен родов, которые занимают в данном обществе наиболее высокое положение и члены которых преимущественно занимают наиболее видное место в системе власти. Обычно эта группа, хотя и открытая «снизу» (пополняемая по воле монарха новыми родами) бывает и формально отличима от всей массы высшего сословия, верхушку которого составляет (наличием родового титула, рядом особых привилегий и т. п.).

Можно выделить четыре основных пути складывания аристократии: 1) потомки родовой верхушки (разных родов) сплачиваются вокруг правителя централизованного государства, образуя в нем высшую социальную группу; 2) при образовании единого государства в высшую знать конституируются независимые местные династы (в ряде случаев сохраняющие свои владения, а в ряде случаев - лишенные их или независимого ими управления); 3) правящий род разрастается со временем в заметную социальную группу, разделяясь на ряд отдельных патронимий; 4) правители формируют этот круг из числа заслуженных лиц, получающих наследственные титулы знатности.
Если почти во всех европейских странах эта группа достаточно определенна (роды, принадлежащие к аристократии, обладают наследственными родовыми титулами), то в отношении азиатских стран, особенно дальневосточных, вопрос стоит сложнее, поскольку титулы там, если и существуют, то обычно не передаются по наследству, а в ряде случаев никаких формальных отличий эта группа может и вовсе не иметь, и ее положение в обществе определяется лишь объективно - по факту доминирования в системе власти именно ее представителей. Но, так или иначе, во всех традиционных обществах (за исключением лишь некоторых деспотий типа Османской, в которых наличие каких бы то ни было патронимических линий, наследственно сохранявших высокое положение, не допускалось не только принципиально, но и на практике) такая группа может быть выявлена.

Разница между обществами аристократическими и бюрократическими (а все традиционные общества могут быть отнесены либо к одному, либо к другому из этих типов) заключается не в наличии или отсутствии в них аристократии, а в наличии или отсутствии юридически оформленных привилегий для ее представителей. При этом степень фактической концентрации власти в руках этой группы может отличаться очень сильно, а может и крайне незначительно (например, в ряде вполне бюрократических обществ даже при отсутствии формальных преимуществ доля представителей аристократических родов в административном аппарате может быть такой, что позволяет говорить об их доминировании). 
Что касается обществ традиционного Дальнего Востока (стран ареала распространения китайской политической культуры), то приходится констатировать наличие противоречия между принятыми там принципами и социальной практикой. Традиционная дальневосточная система в принципе не допускала возникновения потомственного привилегированного сословия: высший слой чиновничества там не мог юридически обеспечить своим детям столь же высокое положение в служебной иерархии (мог только гарантировать поступление на службу), обладатели титулов знатности не могли передавать их наследству, члены древних служилых родов, родовитых кланов, «сильных домов» никак формально не отличались от простолюдинов, если не были чиновниками, а служили далеко не все члены таких семей.

Эти общества по принципу своего устройства были бюрократическими, поэтому наличие аристократии как признаваемой государством наследственной группы (кроме потомков правителей) нехарактерно для классических вариантов традиционной дальневосточной системы. Хотя слой лиц, обладавших рангами в силу своего происхождения, имелся и в этих случаях, это, как правило, были родственники правящего дома (такие лица, не неся обязанностей действительной службы, были формально равны полноправному ранговому чиновничеству, т. к. их наследственные титулы соответствовали одному из общегосударственных рангов). Обычно их было относительно немного, но иногда этот слой вырастал до социально значимых размеров ${ }^{1}$.

Однако аристократическая традиция вовсе не была чужда этому региону. Первые китайские государства Шан (Инь) и Чжоу носили аристократический характер ${ }^{2}$ : за представителями определенного социального ранга был закреплен и набор соответствующих социальных благ. В эпоху централизованных империй аристократическая традиция отошла в тень (тем более что к середине III в. до н. э. большая часть знати была истреблена в войнах). В Цинь (221-207 до н. э.) и Хань (206 г. до н. э. -220 г. н. э.) круг аристократии сузился до членов императорского рода и ограниченного круга лиц, обладавших титулами в силу генеалогического родства: в Хань к аристократии фактически относились только родственники императора

\footnotetext{
${ }^{1}$ В империи Мин к концу династии численность близких и дальних родственников, не занимавших должностей, но имевших ранги, титулы и звания, превысила 100 тыс. человек (У Хань. Жизнеописание Чжу Юань чжана. М., 1980. С. 230).

2 Крил Х. Г. Становление государственной власти в Китае. Империя Западная Чжоу. СПб., 2001. С. 228; Крюков М. В., Софронов М. В., Чебокасров Н. Н. Древние китайцы: проблемы этногенеза. М., 1978. С. 170.
}

и члены семей императриц и вдовствующих императриц $^{3}$.

В раннее средневековье в результате завоевания Северного Китая кочевыми племенами аристократическая тенденция в течение нескольких столетий вновь просматривается весьма отчетливо. В период Южных и Северных династий (420-589), когда право рекомендаций на службу перешло в руки представителей местных кланов, которые, естественно, предпочитали выдвигать родственников, аристократия возродилась именно на этой новой основе: практически только дети лиц, получивших высокую «категорию качества» и поступивших на службу, могли рассчитывать сами получить соответствующую оценку; поскольку же от высоты оценки зависела и высота поста, сложились семьи высокоранговые, второстепенные, меньшие и просто годные для службы ${ }^{4}$. B III-VI вв. аристократический статус был формально связан с обладанием 2-й из «деревенских категорий», открывавшей ее обладателям путь к высшим должностям. Появились семьи, члены которых постоянно обладали этой категорией. С разделением должностей на «чистые» и «грязные» первые стали привилегией аристократов, занимавших их в юном возрасте и без экзаменов. На Юге верхнюю ступень социальной лестницы заняли так называемые изяизу (первостатейные или старые кланы) ${ }^{5}$. С 490 г. аристократические роды появляются и на Севеpe. В Северном Вэй титулы знатности китайского образца стали наследственными, и положенные им земельные пожалования с определенным числом слуг, переходя также по наследству, позволили им превратиться в крупных землевладельцев. В самом конце V в. сложилась аристократическая иерархия в виде 5 китайских и 8 табгачских родов высшей знати, ниже которой стояли еще 4 категории китайских и соответствующих им табгачских родов ${ }^{6}$.

В дотанский и раннетанский периоды власть на высшем уровне также была сконцентрирована в руках небольшого числа особо сильных кланов. Аристократическая элита общегосударственного значения во главе с образовавшимися к концу VII в. семью «великими фамилиями» в целом включала 23 рода, для которых было характерно заключение браков в своей среде (причем браки с представителями низких родов и общинниками были уголовно наказуемы). В целом в Тан (618-907), в отличие от

${ }^{3}$ Chu Tung-tsu. Han Social Structure. Seattle-London, 1972. P. 75$79,86$.

${ }^{4}$ Ebrey P. B. The Aristocratic Families of Early Imperial China. Cambridge, 1978. P. 17-19.

${ }^{5}$ Крюков М. В., Малявин В. В., Софронов М. В. Китайский этнос на пороге средних веков. М., 1979. С. 54-59.

${ }^{6}$ Там же. С. $31,33$. 
более ранних времен, аристократические роды выступали главным образом как потомственные профессиональные чиновники ${ }^{7}$, причем некоторые роды к этому времени существовали более тысячелетия ${ }^{8}$. В период Пяти Династий (907-960) происходит постепенное падение роли аристократии, а при централизованных империях последующего периода круг наследственной аристократии вновь ограничивается родственниками правящего дома; хотя при правлении монгольской (Юань, 12711368) и маньчжурской (Цин, 1644-1911) династий существовали титулы знатности, но они не передавались по наследству всем членам рода ${ }^{9}$.

Страны же Дальнего Востока и Юго-Восточной Азии, находившиеся в сфере влияния китайской культуры и воспринявшие соответствующие принципы социальной и административной структуры, сохраняли значительный потенциал изначально присущей им аристократической традиции, которая при ослаблении по тем или иным причинам китайского влияния прорывалась наружу и проявляла себя достаточно зримо.

Аристократическими были все три корейских раннесредневековых государства, хотя состав аристократии был разным в каждом из них. В Когурё она была представлена слоем так называемых гa (достаточно самостоятельных правителей отдельных районов); в меньшем по размеру и более централизованном Пэкче образовывала придворный столичный круг, включавший 8 родов; в Силла была ограничена родственниками правящего рода (в Силла престол последовательно занимали представители трех родов - Пак, Сок и Ким), число которых за несколько столетий существования династии возросло до нескольких сот, они охватывались понятием чинголь («истинная кость»). В период Корё (918-1392) аристократия не была, как в Силла, юридически обособленной группой. Родственников основателя династии было не так много, чтобы они могли представлять собой заметную социальную группу, да и государство строилось в дальнейшем по образцу Сунского Китая, так что аристократического сословия как такового созда-

\footnotetext{
${ }^{7}$ Twitchett D. The Composition of the T'ang Ruling Class Class // Perspectives on the T'ang. New Haven-London, 1973. P. 50-51, 55-56, 58, 60.

${ }^{8}$ На примере клана Цуй из Полина (первый представитель которого служил в цензорате в 86-72 гг. до н. э., а последний умер в 947 г.) видно, что и в V-VI вв., и в танский период его представители служили в высших и старших рангах; больше половины браков члены клана заключали с другими 7 виднейшими родами, а на все 29 старейших родов (ведущих начало со времени периода Южных и Северных династий) приходилось $82 \%$ браков членов клана (Ebrey P. B. The Aristocratic Families of Early Imperial China. P. 63, 95, 106, 108, 112).

${ }^{9}$ Hucker C. O. A dictionary of official titles in Imperial China. Stanford, 1985. P. 67.
}

но не было. Однако аристократическая прослойка, хотя и неформально, существовала: к ней, помимо членов правящего рода (имевших особые титулы) и членов родов фаворитов (фактических правителей, создавших «параллельные» династии, подобно сёгунским в Японии), можно отнести наиболее знатные роды, насчитывающие 8-9 поколений служилых предков или происходивших от правителей Силла ${ }^{10}$. При следующей династии Ли аристократии также юридически не существовало (хотя в конце XV в. 77 родов имели репутацию «знатных», а в конце XVI в. 22 рода вели происхождение с периода Корё), никаких преимуществ их представители не имели. Однако к концу XVII в. реально выделилась аристократическая прослойка полёль из десятка наиболее влиятельных родов, связанных брачными узами друг с другом и с династией и игравших определяющую роль в жизни страны (на протяжении 500 лет состав первой десятки кланов частично менялся, но в целом удельный вес ее в составе высшего чиновничества возрастал).

В Японии в V-VI вв. помимо императорского клана, занимавшего особое положение, сложился социальный слой, состоявший из родов, имевших потомственные родовые титулы - звания-кабанэ (в 815 г. был составлен свод всех японских родов «Синсэн сёдзироку» ${ }^{11}$ ). Однако все чиновничество в целом практически исчерпывалось представителями носителей кабанэ (или им равных зарегистрированных родов), и аристократию составил круг самых знатных родов: при введении реформой 684-685 гг. 8 титулов наиболее знатные и влиятельные роды были причислены к первым трем из них - махито, асоми и сукунэ (титул махито первоначально был пожалован 13 родам, титул асоми - 52) ${ }^{12}$.

В чжурчжәньском государстве Цзинь аристократия была представлена императорской семьей, возглавлявшей мощный клан Ваньянь (состоявший к 1183 г. из 170 семей и насчитывавший 982 человек), и еще 8 знатнейшими родами ${ }^{13}$. В Бохае аристократию составляли ближайшие родственники монарха (занимавшие высшие и наиболее ответственные должности), а также представители 6 наиболее знатных родов ${ }^{14}$, которые и формировали

\footnotetext{
${ }^{10}$ Волков С. В. Чиновничество и аристократия в ранней истории Кореи. М., 1987. С. 199-200.

${ }^{11}$ Мещеряков А. Н. Древняя Япония: буддизм и синтоизм. М., 1987. C. 176.

12 Грачев М. В. Формирование древнеяпонского чиновничества в VII - начале VIII в. (дис. канд. ист. наук). М., 1998. С. 25, 31-34, 39, 42, 80.

13 Воробьев М. В. Чжурчжэни и государство Цзинь. М., 1975. C. 126,142 .

${ }^{14}$ Е Лун-ли. Цидань го чжи (История государства киданей). М., 1979. С. 335.
} 
верхушку чиновничества (среди последнего известны представители 49 различных родов, большинство из которых мохэские, но встречаются китайские, когурёские и силлаские) ${ }^{15}$. В тангутском обществе аристократию образовывали родовые старшины (обособление старшинской родовой верхушки произошло в Х в.). С образованием государства Си Ся эта социальная иерархия была закреплена структурой государственного аппарата. Представители старшинских родов заняли в нем места в соответствии со своей иерархией; верхушку составляли многочисленные родственники императора ${ }^{16}$.

Во Вьетнаме аристократия первоначально сложилась как группа крупных земельных собственников, которая после 880 г. (фактического освобождения от власти Китая) взяла власть в стране, но не в лице одной династии, а ряда борющихся группировок. Основой ее организации были аристократические роды хо, из поколения в поколение собиравшие доходы с определенной группы общин и занявшие свое положение явочным порядком, а не по воле китайской власти. Впоследствии крупнейшие из этих родов превратились в политически независимых правителей шыкуанов или их подчиненных разного уровня. При династии Чан (1226-1400) аристократия возглавлялась сыновьями правителя и принцами крови, которые в зависимости от титула получали кормовые районы. По мере разрастания рода Чан все титулованные служилые верхи стали состоять почти исключительно из его членов, которые пользовались правом наследования титула (с понижением в зависимости от отдаленности родства с императорами) ${ }^{17}$. При последующих династиях аристократия формировалась также за счет потомков императоров и других членов правящего рода, хотя членство в этом кругу было ограничено определенным числом поколений.

Таким образом, социальная группа, представлявшая собой наследственную аристократию, независимо от того, была ли она законодательно оформлена, в том или ином виде имелась практически во всех государствах традиционного Дальнего Востока. Но место, занимаемое ею в системе власти (а это для данного региона практически означает, какую долю представители аристократии составляли среди высшего чиновничества), могло отличаться весьма значительно, вплоть до диаметрально противоположного (когда в одном случае

\footnotetext{
${ }^{15}$ Государство Бохай (698-926 гг.) и племена Дальнего Востока России. М., 1994. С. 50.

16 Кычанов Е. И. Очерк истории тангутского государства. М., 1968. C. 101-102, 104, 107.

17 Деопик Д. В. История Вьетнама. Ч. 1. М., 1994. С. 61-62, 146147; История Вьетнама М., 1983. С. 128,182.
}

монополия аристократии на власть является абсолютной, а в другом она практически устранена от государственного управления).

В чисто аристократических обществах все высшее чиновничество комплектуется исключительно из представителей аристократии. Так было в первых китайских государствах эпох Шан и Чжоу (где восходящая социальная мобильность в принципе отсутствовала) и, например, в раннесредневековых корейских государствах, где высшие чиновные ранги законодательно закрепились за аристократией (в Когурё это были высшие чины с 1-го по 4-й включительно из $12^{18}$, в Сила - с 1-го по 5-й из 17) ${ }^{19}$.

С другой стороны, наиболее деспотические или наиболее бюрократизированные режимы сознательно ограничивали роль знатных родов, в том числе и членов правящего рода. В Ранней Хань к знати принадлежало лишь 21,8 \% высших чиновников ${ }^{20}$. В минском Китае (1368-1644) принцы императорской крови с начала XV в. не привлекались к управлению, как чаще всего и другие императорские родственники и родственники императриц; большинство чиновников (около $60 \%$ ) вообще не имели служащих одновременно с ними представителей своего клана, особенно в центральном аппарате (где не имели родственников 88,4\%, имели по одному родственнику 9,7 \%, по два - 1,3\% и по три - 0,6\%) ${ }^{21}$. В эпоху Сун (960-1126) представители знати составили лишь 23,5\% высшего чиновничества, а половина вообще происходила из неслужилых семей и считалось хорошим тоном подчеркивать свое незнатное происхождение ${ }^{22}$. В Корее в первое время после установлении власти династии Ли (1392) членам правящего рода на протяжении четырех поколений запрещалось сдавать экзамены и поступать на службу, а многие представители древнейших кланов не поднимались выше рядовых латников. В предшествующий период Корё доля представителей наиболее знатных родов среди высшего чиновничества была очень невелика (в среднем 7,7 \%), а 44,7 \% (в некоторые периоды - до 63,2 \% ) происходило даже из неслужилых семей 23.

\footnotetext{
${ }^{18}$ Самгук саги (Исторические записи Трех государств). Т. 2. Пхеньян, 1959. С. 293.

${ }^{19}$ Волков С. В. Чиновничество и аристократия. С. 178-179.

${ }^{20}$ Eberhard W. Social Mobility in Traditional China. Leiden, 1962. P. 24.

${ }^{21}$ Parsons J. B. The Ming Dynasty Bureaucracy: Aspects of Background Forces // Chinese Government in Ming Times. NY.-L.,1969. P. 207.

${ }^{22}$ Ho Ping-ti. The Ladder of Success in Imperial China. Aspects of Social Mobility 1368-1911. NY.-L., 1962. P. 260.

23 При этом доля аристократии отнюдь не возрастала, как следовало бы ожидать: период Корё длился около 500 лет и если бы все (или большинство) детей этой группы достигали
} 


\section{Исторический журнал: научные исследования № 2 (14) • 2013}

Вообще же (если власть не проводит сознательную политику по ограничению доступа к власти представителей знатных родов) степень монополизации аристократией высших эшелонов государственного аппарата бывает обычно весьма велика, причем часто речь идет об очень небольшой группе родов (в пределах 10 \% от всех), представители которой и составляют большинство высшего чиновничества.

В частности, в Японии в тот период, когда она заимствовала китайские принципы организации госаппарата (VII-IX вв.) степень монополизации аристократией государственных постов была крайне высока. Там не только высшее, но и среднее звено государственного управления находилось в руках наиболее знатных родов: только 4 рода (1,4\% всех родов) дали 43,3\% чиновников 1-5-го рангов, вместе с еще 5 родами (всего $3,2 \%$ ) - почти $2 / 3(63,3 \%)$, а с еще 16 родами (всего 8,8 \%) более $3 / 4(80,7 \%)^{24}$. Высокой была «аристократизация» государственного аппарата в чжурчжэньской империи Цзинь, где один только правящий клан давал от четверти до трети чиновников в важнейших ведомствах, а среди высших чиновников на представителей 8 знатнейших родов приходилось 146 человек, тогда как на прочих - только 9025 .

В период Южных и Северных династий (420589), на Юге в летописях фигурируют по нескольку десятков лиц, принадлежавших к одному роду и находившихся в родстве не далее четвероюродных братьев: в «Цзинь шу», например, встречается 89 представителей рода Ван и 20 представителей рода Лу), в «Сун шу» за 50 лет - 18 представителей рода Цзань (все двоюродные братья и ближе) ${ }^{26}$. На Севере степень монополизации государственного управления представителями одних и тех же родов была, по-видимому, еще выше («Вэйшу» упоминает 61 Ли из Лунси, 36 Лу из Фаньяна и т. д.) ${ }^{27}$. В Сун (420-478 гг.) 48 \% шаншуланов (секретарей ведомства чинов) принадлежали к императорской фамилии, 36 происходили из аристократии и только 16 - из незнатных фамилий ${ }^{28}$. В Тан доля предста-

положения родителей, число чиновников, имеющих 8 и более поколений предков, постоянно увеличивалась бы просто в силу времени. Она достигла наивысшего показателя в первой половине XIII в., после чего стала уменьшаться (Волков С. В. Чиновничество и аристократия. С. 202-203, 206).

24 Подсчитано по материалам: Грачев М. В. Формирование древнеяпонского чиновничества в VII - начале VIII в.

25 Воробьев М. В. Чжурчжэни и государство Цзинь. С. 126-129, 172.

${ }^{26}$ Ebrey P. B. The Aristocratic Families of Early Imperial China. P. 21-22.

27 Ibid. P. 26

${ }^{28}$ Крюков М. В., Малявин В. В., Софронов М. В. Китайский этнос на пороге средних веков. С. 29, 32. вителей знати составила среди высшего чиновничества 68,8 \%, в период Пяти Династий (907-960) всего лишь 20,9\% ${ }^{29}$, но и в это время выделяются 88 родов (6 из них принадлежали к высшей знати уже в IV-VI вв., а возникли еще в эпоху Хань), к которым из 3300 упомянутых в летописи лиц принадлежал 881 человек ${ }^{30}$.

Интересную картину концентрации власти в руках наиболее знатных родов дает Корея периода правления династии Ли, где в XVII-XIX вв. «аристократизация» усилилась настолько, что оказала влияние на результат по всему периоду. В общей сложности 6472 высших чиновников этого периода ${ }^{31}$ принадлежали к 581 роду, причем единственными представителями своего клана оказались лишь 195 человек (3\%). При этом почти четверть чиновников $(22,4 \%)$ происходила всего лишь из 10 родов (1,7\% всех), всего 57 родов (9,8\% всех родов) дали $59,4 \%$ всех чиновников, а более $4 / 5(81,5 \%)$ всего этого контингента были выходцами из 148 родов ${ }^{32}$. Следует иметь в виду, что при династии Ли круг родов, поставлявший культурную элиту страны (представители которых сдавали экзамены на ученые степени) был значительно шире, насчитывая более 1440 родов, но $60 \%$ их в составе старшего и высшего чиновничества не были представлены вовсе. Данные о лауреатах экзаменов того же периода еще более показательны: около 72 \% всех лауреатов конкурса на ученые степени (сэнвонов и иинса) дали 84 знатных рода (всего лишь 5,8 \% всех родов), причем 24,3\% дали 10 родов; в то же время роды с единственным представителем, составляя 40,7\% всех родов, дали только $1,5 \%$ всех лауреатов ${ }^{33}$.

Обобщая приведенные данные, можно заключить, что в традиционных обществах Дальнего Востока с преобладанием аристократического начала несколько самых влиятельных родовых кланов (около $2 \%$ от всех) давали обычно от четверти до 40 \% высших лиц, а около $10 \%$ всех кланов - 60-80\%. Соотношение между числом высших лиц за определенный период и числом поставивших их родов тут бывает порядка 10 : 1, причем кланы, давшие лишь по одному представителю, составляя более 40 \% всех кланов, дают в со-

\footnotetext{
${ }^{29}$ Ho Ping-ti. The Ladder of Success in Imperial China. P. 260.

${ }^{30}$ Eberhard $W$. Conqueres and Rulers. Social forces in medieval China. Leiden, 1965. P. 115-121.

31 Те, чьи биографии помещены в «Словарь выдающихся сановников Кореи» (Чосон мёнсин чжон. Т. 1-2. Сеул, 1962).

${ }^{32}$ Волков C. В. Клановый состав высшего корейского чиновничества периода Чосон // Корея: история и современность. М.; Сеул, 2008. С. 73-75.

33 Чхве Джинок. Чосон сидэ сэнвон чинса ёнгу (Исследование обладателей степеней сэнвон и чинса периода Чосон). Сеул, 1998. С. 141, 267, 292-293.
} 


\section{Культура и культуры в историческом контексте}

вокупности лишь 2-3 \% высших лиц. В обществах с преобладанием бюрократического начала это соотношение принципиально иное -2 : 1или 3 : 1 ; доля единственных представителей своего рода возрастает до 40 \% и даже более. Аристократиче- ские (или с преобладанием аристократического начала) азиатские общества по показателям представительства во властных структурах наиболее видных родов в среднем мало отличаются от аналогичных европейских.

\section{Список литературы:}

1. Волков С. В. Чиновничество и аристократия в ранней истории Кореи. М., 1987.

2. Воробьев М. В. Чжурчжэни и государство Цзинь. М., 1975.

3. Государство Бохай (698-926 гг.) и племена Дальнего Востока России. М., 1994.

4. Крил Х. Г. Становление государственной власти в Китае. Империя Западная Чжоу. СПб., 2001.

5. М. В., Малявин В. В., Софронов М. В. Китайский этнос на пороге средних веков. М., 1979.

6. Кычанов Е. И. Очерк истории тангутского государства. М., 1968.

7. Чхве Джинок. Чосон сидэ сэнвон чинса ёнгу (Исследование обладателей степеней сэнвон и чинса периода Чосон). Сеул, 1998.

8. Chu Tung-tsu. Han Social Structure. Seattle-London, 1972.

9. Eberhard W. Conqueres and Rulers. Social forces in medieval China. Leiden, 1965.

10. Eberhard W. Social Mobility in Traditional China. Leiden, 1962.

11. Ebrey P. B. The Aristocratic Families of Early Imperial China. Cambridge, 1978.

12. Ho Ping-ti. The Ladder of Success in Imperial China. Aspects of Social Mobility 1368-1911. NY.-L., 1962.

13. Parsons J. B. The Ming Dynasty Bureaucracy: Aspects of Background Forces // Chinese Government in Ming Times. NY.-L.,1969.

14. Twitchett D. The Composition of the T'ang Ruling Class Class // Perspectives on the T'ang. New Haven-London, 1973.

\section{References (transliteration):}

1. Volkov S.V. Chinovnichestvo i aristokratiya v ranney istorii Korei. M., 1987.

2. Vorob'ev M.V. Chzhurchzheni i gosudarstvo Tszin'. M., 1975.

3. Gosudarstvo Bokhay (698-926 gg.) i plemena Dal'nego Vostoka Rossii. M., 1994.

4. Kril Kh.G. Stanovlenie gosudarstvennoy vlasti v Kitae. Imperiya Zapadnaya Chzhou. SPb., 2001.

5. Kryukov M.V., Malyavin V.V., Sofronov M.V. Kitayskiy etnos na poroge srednikh vekov. M., 1979.

6. Kychanov E.I. Ocherk istorii tangutskogo gosudarstva. M., 1968.

7. Chkhve Dzhinok. Choson side senvon chinsa engu (Issledovanie obladateley stepeney senvon i chinsa perioda Choson). Seul, 1998.

8. Chu Tung-tsu. Han Social Structure. Seattle-London, 1972.

9. Eberhard W. Conqueres and Rulers. Social forces in medieval China. Leiden, 1965.

10. Eberhard W. Social Mobility in Traditional China. Leiden, 1962.

11. Ebrey P.B. The Aristocratic Families of Early Imperial China. Cambridge, 1978.

12. Ho Ping-ti. The Ladder of Success in Imperial China. Aspects of Social Mobility 1368-1911. NY.-L., 1962.

13. Parsons J.B. The Ming Dynasty Bureaucracy: Aspects of Background Forces // Chinese Government in Ming Times. NY.-L.,1969.

14. Twitchett D. The Composition of the T'ang Ruling Class Class // Perspectives on the T'ang. New Haven-London, 1973. 